\title{
Fake And Counterfeit Drugs In The Health Sector: The Role Of Medical Doctors.
}

\author{
Dora Akunyili
}

\author{
Dr. Dora Akunyili, is the Director, \\ National Agency for Food and Drug \\ Administration and Control (NAFDAC), \\ Nigeria.
}

Drugs play pivotal role at all levels of healthcare. They are useful for maintenance of health, diagnosis, prevention, treatment, or mitigation of diseases/disorders. However, due to immense benefits derived from drugs and their global usage, some unscrupulous persons see them as a means of making fast money, thus they indulge in producing and circulating fake/counterfeit drugs.

Drug counterfeiting is primarily a health related crime with enormous economic ramifications. Fake/counterfeit drugs provide illegal benefits for the perpetrators at the expense of the patients, healthcare system, practitioners, the drug regulatory authority and the pharmaceutical industry whose products are counterfeited. It poses a growing threat, especially to the developing countries, where the most counterfeited medicines are those used to treat life-threatening conditions such as malaria, tuberculosis and HIV/AIDS. Fake drugs therefore complicate the alrcady complex and poor prognosis of the global health care situation, particularly in the developing countries.

In the bid to safeguard the public through eradication of fake drugs and substandard regulated products from the society, government established NAFDAC.

\section{THE NAFDAC MANDATE.}

The National Agency for Food and Drug Administration and Control (NAFDAC), was established by Decree No 15 of 1993 (as amended), to control and regulate the manufacture, importation, exportation, distribution, advertisement, sale and use of food, drugs, cosmetics, chemicals/detergents, medical devices and packaged water including all drinks (referred to as regulated products).

The scope of this mandate puts the responsibility of safeguarding public health on the Agency, and this touches on the life of every Nigerian.

\section{WHAT ARE FAKE/COUNTEREEIT DRUGS?}

Despite the global nature of fake/counterfeit drugs, the International Community does not have a harmonized definition of fakc/counterfeit drugs to reflect its global nature and capture its entire essence. This is because it is seen from different perspectives by different countries.

The World Health Organization (WHO) defines fake/counterfeit medicine as "... one, which is deliberately and fraudulently mislabeled with respect to identity and/or source. Counterfeiting can apply to both branded and generic products and counterfeit products may include products with the correct ingredients or with the wrong ingredients, without active ingredients, with insufficient active ingredients or with take packaging" "

NAFDAC has identified various forms of fake/counterfeit drugs in Nigeria, which include:

* Jrugs with no active ingredient(s) e.g. having only lactose or even chalk in capsules and tablets, e.g. olive oil in Supradyn capsules.

* Drugs with insufficient active ingredients c.g. $41 \mathrm{mg}$ Chloroquine instead of $200 \mathrm{mg}, 50 \mathrm{mg}$ Ampicillin as against $250 \mathrm{mg}$.

* Drugs with active ingredient(s) different from what is stated on the packages e.g. Paracetamol tablets packaged and labelled as Fansidar (Sulphadoxine + Pyrimethamine).

* Clones of fast moving drugs - these are drugs with the same quantity of active ingredients as the genuine original brand.

* Drugs without full name and address of the manufacturer.

* Herbal Preparations that are toxic, harmful, ineffective or mixed with orthodox medicine.

* Expired drugs or drugs without expiry date, or expired and re-labelled with the intention of extending their shelf-life.

* Drugs not certified and registered by NAFDAC. 
Fake drugs know no boundaries, they are found in practically all nations of the world. Countries with strict regulation like the USA, have recorded increment in the prevalence of fake drugs in the past three years.

\section{REPORTED MA JOR TRAGEDIES ASSOCIATED WITH SUBSTANDARD AND FAKE/COUNTERFEIT DRUGS.}

There have been several reports of deaths from fake/counterfeit and substandard drugs from all over the world. A few of such examples are:

i. In 1938, in U.S.A, a sulphanilamide elixir formulation error occurred when a dispensing pharmacist used toxic ethylene glycol solyent instead of the non-toxic propylene glycol solvent. This error caused the deaths of about seventy-six (76) patients, mostly children. The incident inspired the 1938 U.S. Food, Drugs and Cosmetics Act, which created a requirement for independent premarketing approval of new pharmaceutical products and established the U.S. Food and Drug Administration.

ii. In 1999, at least 30 people died in Cambodia after taking counterfeit antimalarials prepared with Sulphadoxine + pyrimethamine (an older, less effective antimalarial) which were sold as Artesunate.'

iii. During the meningitis epidemic in Niger between 1995 and 1996, over 50000 people were inoculated with fake vaccines, received as a gift from a country which thought they were safe. The exercise resulted in 2,500 deaths. ${ }^{+}$

iv. In Nigeria, due to poor reporting system, cases of worsening disease conditions or deaths due to fake drugs abound, but unfortunately we don't have statistics to support them.

In addition, due to cultural cleavages, deaths are sometimesattributed to witchcrafts from the "wicked ones" or "enemies". This again does not help our reporting system. However, few reported cases are:

- In 1989, at the University of Nigeria Teaching Hospital (UNTH) Enugu, children with malaria, treated with poorly compounded chloroquine syrup, developed chloroquine poisoning complications, which caused the deaths of four (4) children.

- In 1990, the "Paracetamol syrup disaster" occurred when 109 children died in Ibadan and Jos, after taking paracetamol syrup produced with the toxic ethylene glycol solvent instead of propylene glycol.
This tragedy occurred more than fifty years after the U.S.A. ethylene glycol tragedy.

- Fake cardiac stimulant (Adrenalin) was reported by Nigerian Guardian Newspaper to have contributed to the death of two children during open-heart surgery at UNTH, Enugu. Further investigations by NAFDAC revealed that even the muscle relaxant used was substandard and the infusion was not sterile, and both were purchased from unregistered pharmacies manned by non-professionals. Even the Adrenalin, which was supplied by a registered pharmacist, was purchased from an open drug market at Onitsha.

These are just a few of the hazardous cases of fake drugs; however they also have socioeconomic implications.

\section{IMPLICATIONS OF COUNTERFEIT/FAKE DRUGS}

Counterfeiting of medicines is the greatest evil of our time and the highest weapon of terrorism against public health, as well as an act of economic sabotage. It is an ill wind that blows nobody good.

- The evil of fake drugs is worse than the combined scourge of malaria, HIV/AIDS and armed robbery put together. This is because malaria can be prevented, HIV/AIDS can be avoided and armed robbery may kill a few at a time, but counterfeit/fake drugs kill en mass.

* The social problem posed by hard drugs, cocaine, heroine etc. cannot also be compared with the damage done by fake drugs, because illicit drugs are taken out of choice, and by those that can afford them, but fake drugs are taken by all and anybody can be a victim.

* Fake drugs have embarrassed our healthcare providers and eroded the confidence of the public on our healthcare delivery system. This development led to treatment failures, organ dysfunction/damage, worsening of chronic disease conditions and the death of many Nigerians. The situation became so bad that even when patients were treated with genuine antibiotics, they no longer respond positively due to resistance induced by previous intake of fake/counterfeit antibiotics.

* Nigerians who can afford it, travel abroad to obtain medical treatment for simple illnesses that can be managed at home because of fake drugs.

* Individual hospitals, clinics or even practitioners often resorted to importing drugs for use in their practice, thereby encountering distractions from their core competence which is caring for the 
patients.

* Most of our local pharmaceutical industries that are producing genuine drugs, employing labour and boosting our economy, could not break even because of unfair competition with drug fakers, who are only paying for packaging and probably freighting without spending on active ingredients, which are the most expensive components of any drug. They even found it difficult to export because of the bad image created by fakers.

* The fakers even became agents of waste disposal to their collaborators from other countries to dispose expired drugs by importing them into Nigeria.

\section{FACTORS THAT ENCOURAGE DRUG COUNTERFEITING}

Medicines are high-value items in relation to their bulk and the demand for medicines is endless. In many countries, especially among the poor and developing nations, some of the following factors facilitate the existence of criminal networks that promote drug counterfeiting:

\section{Chaotic drug distribution system}

Drug distribution in Nigeria is very chaotic with drugs marketed like any other commodity of trade. Due to poor regulation over the years, drug markets evolved and got deeply established all over the country despite the illegality of such activities. Almost all drug manufacturers and importers supply to these drug markets. Drug sellers and even health professionals patronize the drug markets, which also service the hawkers that sell in streets and commercial buses.

Efforts made by NAFDAC to create an orderly Drug Distribution System so as to enable the agency phase out the existing disorganized Drug Markets, suffered a set back due to its unacceptability by some Pharmacists who are key stakeholders in drug matters. However, pharmacies around the country are forming drug distribution consortiums known as COPHARM to provide alternative distribution outlets to the markets which are the den of counterfeits.

Inadequate cooperation from government agencies and among professional groups.

Lack of or inadequate cooperation between professionals especially in the healthcare delivery system fuels counterfeiting of drugs. This is so because doctors especially those in private practice readily procure drugs without inputs from pharmacists whose expertise is on drug matters. This makes it more likely for doctors to buy fake drugs. Similarly, pharmacists, nurses and non professionals, readily prescribe and dispense drugs without due consultation with the medical doctors who are experts in clinical practice. The effect of dispensing doctors, prescribing pharmacists/ nurses etc becomes worrisome from this WHO report. "Many prescribers, as well as drug retailers, earn their living by selling medicine and not by charging consultation fees. It has been shown in many countries that prescribers who earn money from dispensing medicines consistently prescribed more drugs than those who do not make money from dispensing. In a study in Zimbabwe, dispensing doctors prescribed antibiotics to $58 \%$ of their patients compared to non-dispensing doctors who prescribed antibiotics to $48 \%$ of their patients." This presents a self-regulatory challenge to the medical practitioners.

Other factors which encourage counterfeiting include:-

\begin{tabular}{|c|c|}
\hline & Irrational use of drugs \\
\hline & $\begin{array}{l}\text { Poor database on health related } \\
\text { activities }\end{array}$ \\
\hline 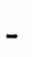 & Insecure and unfriendly environment \\
\hline & $\begin{array}{l}\text { Discriminatory regulation by exporting } \\
\text { countries }\end{array}$ \\
\hline & $\begin{array}{l}\text { Sophistication in clandestine drug } \\
\text { manufacture. }\end{array}$ \\
\hline & Corruption and conflict of interest. \\
\hline
\end{tabular}

\section{MEASURES TAKEN BY NAFDAC TO CURB COUNTERFEITING OF MEDICINES AND OTHER REGULATED PRODUCTS.}

\section{NAFDAC VISION, MISSION, GOAL AND STRATEGIES}

The Management of NAFDAC has resolved that counterfeit medicines must be brought to the barest minimum in the shortest possible time.

Our team believes that we are called to a mission to eradicate this evil and to achieve this; we have a clear vision, set goal and strategies.

\section{Our VISION is "To safeguard public health"}

Our MISSION is "To safeguard public health by ensuring that only the right quality products are manufactured, imported, exported, advertised, distributed, sold and used in Nigeria".

Our current GOAL "is to eradicate fake drugs and other substandard regulated products". 
We have evolved some strategies to achieve our goal and create a strong regulatory environment some of which are:

- Staffre-orientation and motivation.

- Restructuring \& Modernization of our regulatory processes.

- Public enlightenment campaigns.

- Stopping the importation of fake drugs to Nigeria at source.

- Beefing up of surveillance at all ports of entry.

- Mopping up what is already in circulation.

- Monitoring Good Manufacturing Practice (GMP) of local manufacturers.

- Streamlining and strict enforcement of our registration guidelines.

These strategies employed by the Agency have helped to record a lot of successes in the past three years of the present administration.

\section{THE ROLE OF DOCTORS IN ELIMINATING FAKE/COUNTERFEIT MEDICINES:}

Doctors generally have contact with patients at their most vulnerable time; when they are down with an ailment or disorder. Doctors therefore wield an awesome influence on the healthcare of patients. Therefore, it should go without saying that if Doctors resolve to proactively play their role in eliminating counterfeit drugs from their practice, a major achievement in that regard will be recorded. All it requires are simple self regulatory measures that promote rational use, uphold ethical practice, enhance doctors' professional practice and work for the ultimate good of the patient.

The role of medical doctors in the elimination of counterfeit drugs can not be overemphasized. You can do this by;

- Discouraging your patients from indulging in irrational self medication which fuels counterfeiting.

- Endeavoring to use the services of other professionals where necessary in your practice. For example, Pharmacists are we 11 positioned to source for genuine $\mathrm{drugs}$ and help advice you in other areas such as rational dispensing and drug management. More so, you can hold them responsible for any lapses as against untrained hands.

- Ensuring that your hospitals/clinics source drugs from only credible sources $\mathrm{su} \mathrm{ch}$ as the manufacturers or their accredited distributors, registered pharmacy premises, etc. Also advice your patients to do the same when you issue them prescriptions meant to be filled outside the hospitals.

- Insisting on proper examination of the product package for expiry date, spelling errors and other lapses by your pharmacist before purchasing drugs.

- Ensuring that you report all Adverse Drug Reactions including lack of effect to the National Pharmacovigilance Centre as this will help to detect quality defects in drugs, which is often indicative of counterfeit drugs.

Counselling your patients on how to take their drugs and to report suspected ADRs to you for onward reporting to the National Pharmacovigilance Centre.

- Supporting NAFDAC's crusade to eradicate fake drugs and other unwholesome regulated products and create a well-regulated environment. I recommend that rational use of drugs should be a benchmark in our clinical practice.

- Studying and propagating the bimonthly publications of the differences between fake and genuine products in most Nigerian Newspapers by NAFDAC with a view to avoid the buying and using fake drugs.

\section{CONCLUSION.}

As the nation strives towards achieving adequate health care for the populace, NAFDAC's activities and that of stakeholders especially medical doctors towards eradicating fake drugs, are crucial for sustained success to be attained.

We can only combat the menace of fake drugs and other substandard regulated products through team work. It is a win-win approach. NAFDAC cannot do it alone, no matter how zealous or determined we are. NAFDAC is ready to work with doctors in any way possible to eliminate this menace. The national pharmacovigilance programme is one of the steps towards ensuring that doctors have access to safe medicines for use in their practice. To this end NAFDAC has printed ADR reporting forms with prepaid stamps to make it easier to report ADRs, lack of effect and other drug related problems to the Agency. All doctors need to do is to fill the forms properly and send to the national centre. More copies of the form will be made available on request. NAFDAC also have sufficient quantities of guides to help every doctor in Nigeria know what to report and how to report. NAFDAC therefore calls on you to play your role well, so that together we can all eliminate this fake/counterfeit medicine. I am 
confictent that with all these arrangements and your cooperation and support, fake drugs will be a thing of the past in Nigeria. One way to solve this problem and for health practitioners to effectively contribute in eliminating the problem, is by fostering inter professional relationships, thereby tapping from one another's core competence. This will help in frustrating drug counterfeiters.

\section{References}

'WHO Drug Information, Vol. 6, No.2, 1992. Page 41.

${ }^{2}$ WHO Drug Information, Vol. 9, No. 3, 1995, pg. 127

${ }^{3} \mathrm{http} / / \mathrm{www}$.who.int/meidacentre/factsheets/2003/fs2

${ }^{4}$ http://www.who.int/meidacentre/factsheets/2003/fs2

${ }^{5}$ Essential Drugs Monitor Double Issue No. 28\&29

(2000) pg. 9 